Research paper

\title{
Detection, risk factors and molecular diversity of norovirus GIII in cattle in Uruguay
}

\author{
Matías Castells ${ }^{\mathrm{a}, \mathrm{b}, *}$, Rubén Darío Caffarena ${ }^{\mathrm{b}, \mathrm{c}}$, María Laura Casaux ${ }^{\mathrm{b}}$, Carlos Schild ${ }^{\mathrm{b}}$, \\ Felipe Castells $^{\mathrm{d}}$, Daniel Castells ${ }^{\mathrm{e}}$, Matías Victoria ${ }^{\mathrm{a}}$, Franklin Riet-Correa ${ }^{\mathrm{b}}$, Federico Giannitti ${ }^{\mathrm{b}}$, \\ Viviana Parreño ${ }^{\mathrm{f}}$, Rodney Colina ${ }^{\text {a, }}$ \\ ${ }^{a}$ Laboratorio de Virología Molecular, CENUR Litoral Norte, Centro Universitario de Salto, Universidad de la República, Rivera 1350, 50000 Salto, Uruguay \\ ${ }^{\mathrm{b}}$ Instituto Nacional de Investigación Agropecuaria (INIA), Plataforma de Investigación en Salud Animal, Ruta 50 km 11, Estación Experimental La Estanzuela, 70000 \\ Colonia, Uruguay \\ ${ }^{c}$ Facultad de Veterinaria, Universidad de la República, Alberto Lasplaces 1620, Montevideo, Uruguay \\ d Doctor en Veterinaria en ejercicio libre, asociado al Laboratorio de Virología Molecular, CENUR Litoral Norte, Centro Universitario de Salto, Universidad de la \\ República, Uruguay \\ e Centro de Investigación y Experimentación Dr. Alejandro Gallinal, Secretariado Uruguayo de la Lana, Ruta 7 km 140, Cerro Colorado, Florida, Uruguay \\ ${ }^{\mathrm{f}}$ Sección de Virus Gastroentéricos, Instituto de Virología, CICV y A, INTA Castelar, Buenos Aires, Argentina
}

\section{A R T I C L E I N F O}

\section{Keywords:}

Bovine norovirus

Cattle

Diarrhea

Genotypes

Uruguay

\begin{abstract}
A B S T R A C T
Uruguay is a leading exporter of bovine meat and dairy products, and cattle production is one of the principal economic backbones in this country. A main clinical problem faced by livestock farmers is neonatal calf diarrhea (NCD); however, causes of NCD have not been extensively studied in Uruguay. Bovine norovirus (BoNoV) has been proposed as one of the possible etiologies of NCD as experimentally infected calves developed diarrhea and enteropathy, although limited information is available from field surveys. The aims of this study were to determine the frequency of infection, to investigate possible risk factors, and to determine the molecular diversity of BoNoV in Uruguay. A total of 761 samples of feces or intestinal contents from dairy and beef calves were analyzed through RT-qPCR. The overall frequency of detection of BoNoV was $66.1 \%$ with higher frequency in dairy $(70.5 \%)$ than beef $(15.9 \%)$ calves $(p<0.01)$. BoNoV was detected similarly in diarrheic $(78.8 \%)$ and non-diarrheic $(76.2 \%)$ dairy calves $(p=0.50)$. Calves $\leq 2$ weeks of age $(84 \%)$ were infected more often than older $(62.7 \%)$ calves $(p<0.01)$. Phylogenetic analysis confirmed the presence of GIII.1 and GIII.2 genotypes. In addition, we reported the circulation of recombinant strains and the detection of a strain with the recently described novel VP1 genotype. This study represents the first report describing the circulation, the associated risk factors, and the molecular diversity of BoNoV in Uruguay.
\end{abstract}

\section{Introduction}

A main problem that the livestock industry must face is neonatal calf diarrhea (NCD), a complex and multifactorial clinical syndrome of worldwide distribution. Although NCD affects both beef and dairy cattle, it is particularly important in dairy farming as it represents the major cause of mortality of calves before weaning (Urie et al., 2018). NCD leads to economic losses to the livestock industry due to a negative impact on animal wellness with short- and long-term effects on production (Waltner-Toews et al., 1986; Donovan et al., 1998). The causes of NCD outbreaks are poorly known and rarely investigated; also little is known about the prevalence, relative importance, possible interrelationships and pathogenic effects of the numerous microorganisms that have been shown or suggested as a cause of diarrhea (Selman, 1981).

Bovine noroviruses (BoNoVs) have not captured the attention that other pathogens have received and are not included in routine diagnosis for NCD, so their impact on livestock health and production remains unclear (Di Felice et al., 2016). BoNoVs were discovered in 1978, and their pathogenicity is mainly due to lesions in the small intestine,

\footnotetext{
* Corresponding authors at.: Laboratorio de Virología Molecular, CENUR Litoral Norte, Centro Universitario de Salto, Universidad de la República, Rivera, 1350, 50000 Salto, Uruguay.

E-mail addresses: matiascastellsbauer@gmail.com (M. Castells), rodneycolina1@gmail.com (R. Colina).
} 
including villus atrophy with loss and attenuation of the villus epithelium, inducing diarrhea (Woode and Bridger, 1978; Jor et al., 2010; Otto et al., 2011; Jung et al., 2014).

Classified within the genogroup III (GIII) of the Norovirus genus in the Caliciviridae family (Scipioni et al., 2008), BoNoV are non-enveloped viruses with a single stranded RNA genome of positive polarity of approximately $7.5 \mathrm{~kb}$ containing 3 ORFs. Transmission is mainly sustained by the fecal-oral route, and low infectious doses as well as the great diversity of strains increase the risk of infection (Scipioni et al., 2008).

Although BoNoV is studied to a much lesser extent than other viruses that are well known causative agents of NCD such as rotavirus and coronavirus, several studies confirm that BoNoVs are widely present in cattle and sometimes at a high frequency in cases of diarrhea in different countries (van Der Poel et al., 2000; Deng et al., 2003; van Der Poel et al., 2003; Milnes et al., 2007); they are also detected in non-diarrheic calves (Jor et al., 2010). In addition, a serological study indicated that exposure to BoNoV can reach over $99 \%$ of the analyzed samples (Deng et al., 2003).

There have been recognized three genotypes within GIII, namely GIII.1, GIII.2, and GIII.3, being GIII.1 and GIII.2 associated to bovine norovirus, and GIII.3 to ovine norovirus. In addition, several studies have demonstrated the circulation of recombinant strains, with the recombination breakpoint in the ORF1-ORF2 junction genomic region (Bull et al., 2007). Both genotypes GIII.1 and GIII.2, formerly referred to as Jena virus and Newbury-2 virus, respectively, have been shown to be diarrheagenic when inoculated experimentally into calves (Woode and Bridger, 1978; Jor et al., 2010; Otto et al., 2011; Jung et al., 2014).

Uruguay is one of the main exporters of bovine meat (FAO, 2018) and dairy products (IDF, 2013), and cattle production is one of the main economic backbones in this country (DIEA, 2019), however, there are no studies on BoNoV in cattle. The aims of this study were to determine the frequency of infection, to investigate possible risk factors, and to determine the molecular diversity of BoNoV in calves in Uruguay.

\section{Materials and methods}

\subsection{Samples and fecal suspensions}

A total of 761 samples of feces (699) or intestinal contents (62) were collected from dairy (717) and beef (44) calves in Uruguay. The intestinal contents were collected from diarrheic calves that died naturally, and all 699 fecal samples were from live calves. Risk factors for BoNoV infection were only evaluated in dairy calves, as insufficient data was available from beef calves. Fecal samples from dairy calves were categorized as diarrheic (208) and non-diarrheic (235) at the time of sampling (this information was missing for 443 samples); 209 samples came from calves in dairy herds that reported vaccinating the dams against NCD, while 203 came from calves in dairy herds where vaccination against NCD was not practiced (for 412 samples this information was unavailable). Regarding the age of the dairy calves, 127 were up to 1 week old, 180 were in the second week of life, 96 were in the third week of life, 28 were in the fourth week of life, and 10 were more than 4 weeks old. Samples were collected in $2015(n=39), 2016(n=490), 2017$ ( $n=$ 185), and $2018(n=47)$.

\subsection{Viral RNA extraction and reverse transcription}

From all samples, suspensions were obtained after diluting 1:10 (v:v) in phosphate-buffered saline solution, and supernatants were collected after centrifugation at $3000 \mathrm{~g}$ for $20 \mathrm{~min}$ at $4{ }^{\circ} \mathrm{C}$. Viral RNA was extracted using QIAamp ${ }^{\circledR}$ cador ${ }^{\circledR}$ Pathogen Mini Kit (Qiagen ${ }^{\circledR}$ ), following the manufacturer's instructions. Reverse transcription (RT) was carried out with RevertAid ${ }^{\circledR}$ Reverse Transcriptase (Thermo Fischer Scientific ${ }^{\circledR}$ )

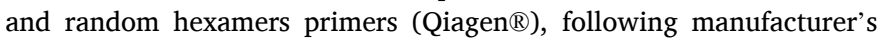
instructions. All RNAs and cDNAs were stored at $-80{ }^{\circ} \mathrm{C}$ until further viral analyses.

\subsection{BoNoV screening and sequencing}

Screening of the samples for GIII BoNoV identification was carried out through a real time polymerase chain reaction (qPCR) targeted to the junction between the ORF1 and ORF2, which is a highly conserved genomic region. Primers, probe and real time PCR conditions were used as described elsewhere (Wolf et al., 2007).

In order to determine the genotypes circulating in the Uruguayan calves, 50 qPCR-positive samples were selected randomly and subjected to amplification of a 517-bp fragment (Wolf et al., 2007). Briefly, $12.5 \mu \mathrm{L}$ of MangoMix ${ }^{\mathrm{TM}}$ (Bioline $\left.{ }^{\circledR}\right), 5 \mu \mathrm{L}$ of cDNA, $4.5 \mu \mathrm{L}$ of nuclease-free water, $1 \mu \mathrm{L}$ of dimethyl sulfoxide, $1.0 \mu \mathrm{L}$ of $10 \mu \mathrm{M}$ SW GIII forw primer and 1.0 $\mu \mathrm{L}$ of $10 \mu \mathrm{M}$ NVGIIIrseq primer were mixed in $0.2 \mathrm{~mL}$ PCR tubes. PCR products were visualized in $2 \%$ agarose gels and positive samples were purified using PureLink ${ }^{\mathrm{TM}}$ Quick Gel Extraction and PCR Purification

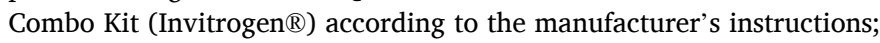
both DNA strands were sequenced at Macrogen Inc. (Seoul, South Korea). Sequences were deposited in GenBank with accession numbers: MT227833-MT227846, and MT765190-MT765209.

\subsection{Phylogenetic analysis}

A phylogenetic analysis was performed in order to determine the BoNoV genotypes circulating in Uruguay. Database sequences were downloaded using BLAST (https://blast.ncbi.nlm.nih.gov/Blast.cgi). Multiple sequences alignment was obtained with ClustalW in MEGA 7 software (Kumar et al., 2016). The nucleotide substitution model that best fit our data and the maximum likelihood tree was obtained with IQTREE (Trifinopoulos et al., 2016).

\subsection{Recombination analysis}

The SimPlot program was used to determine the presence of evidence of recombination in the sequences, with a window size of 50 and a step size of 25. Jena and Newbury2 strains were used as reference sequences for GIII.1 and GIII.2 genotypes, respectively. In order to confirm the evidence, a nucleotide identity matrix and phylogenetic analysis were performed with partial sequences before and after the recombination breakpoint suggested by SimPlot analysis.

\subsection{Statistical analyses}

Categorical data was evaluated with jamovi software (available at https://www.jamovi.org/) using $2 \times 2$ contingency tables and through Pearson's Chi-squared test; in multiple comparisons, the Bonferroni correction was applied. Relative risk (RR) and 95\% confident intervals (CI) were calculated with jamovi software. Numerical data was evaluated with jamovi software using the Shapiro-Wilk test for normality (Shapiro and Wilk, 1965) and when the null hypothesis was rejected Mann-Whitney $U$ test was used (Mann and Whitney, 1947). In all tests, differences were considered statistically significant if the obtained $p$ value was $\leq 0.05$. Graphics were generated using Microsoft ${ }^{\circledR}$ Office Excel, and the line of tendency that best fit the data (evaluated by the $\mathrm{R}^{2}$ value) was obtained with the same program.

\section{Results}

\subsection{BoNoV detection and risk factors}

Bovine norovirus (GIII) was detected in $66.1 \%$ (503/761) of the analyzed samples. The frequency of detection was significantly higher in dairy $70.5 \%(462 / 655)$ than beef $(15.9 \%, 7 / 44)$ calves (RR: $2.85,95 \%$ CI: $2.4-3.4 ; p<0.00001$ ) (Fig. 1a). BoNoV was detected in $67.1 \%$ (469/ $699)$ and $54.8 \%(34 / 62)$ of the samples of feces (live calves) and 
$100 \%$

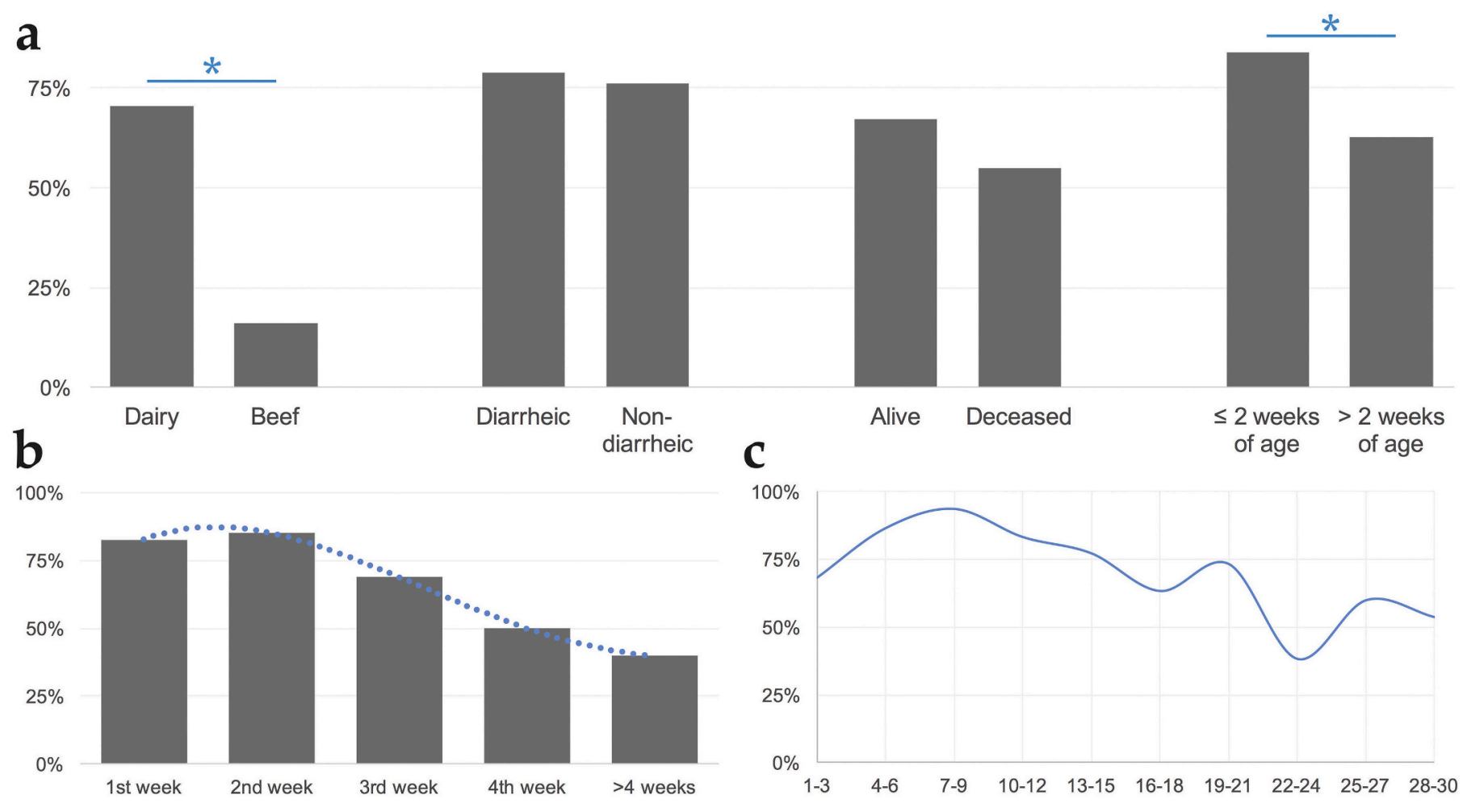

a

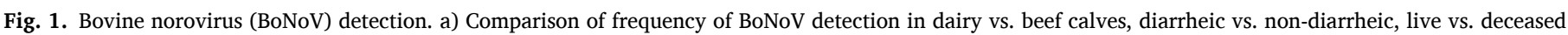

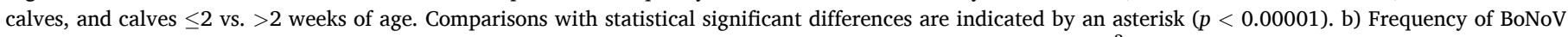

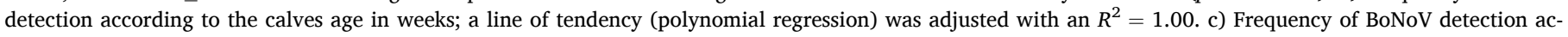
cording to the calves age in days.

intestinal contents (deceased calves), respectively, this difference being non-significant ( $p=0.051)$ (Fig. 1a).

The proportion of BoNoV-positive samples was higher in diarrheic $78.8 \%(164 / 208)$ than non-diarrheic $76.2 \%$ (179/235) calves, although this difference was not statistically significant $(p=0.50)$ (Fig. 1a). Calves born to dams vaccinated against NCD (vaccines include several pathogens but not BoNoV) showed a frequency of detection of $82.8 \%$ $(173 / 209)$ while calves born to dams unvaccinated showed a frequency of detection of $77.3 \%(157 / 203)$, this difference was not statistically significant $(p=0.17)$.

Calves $\leq 2$ weeks of age were more often infected by BoNoV ( $84 \%$, $258 / 307)$ than older calves $(62.7 \%, 84 / 134)$, and this difference was statistically significant (RR: 2.06, 95\%CI: 1.57-2.69; $p<0.00001$ ) (Fig. 1a). The frequency of BoNoV detection in calves in their first, second, third, fourth and after the fourth week of life was $82.7 \%$ (105/ 127), $85 \%$ (153/180), 68.8\% (66/96), 50\% (14/28), 40\% (4/10), respectively (Fig. 1b). The frequency of BoNoV was significantly higher between the age groups: $1 \mathrm{vs} 4,1 \mathrm{vs}>4,2 \mathrm{vs} 3,2 \mathrm{vs} 4$, and $2 \mathrm{vs}>4$, so BoNoV was more frequently detected in calves in their first two weeks of age. This frequency declined with the age, as observed in a line of tendency obtained by a polynomial regression $\left(\mathrm{R}^{2}=1.00\right)$ (Fig. $\left.1 \mathrm{~b}\right)$. Similarly, when the frequency of BoNoV detection was analyzed by the age of the calves in days, a peak between days 7 and 9 was observed (Fig. 1c).

The mean age of the positive calves to BoNoV (11.0 days) was significantly lower than the mean age of the negative ones (14.4 days; $p$ $<0.001$ ) (Fig. 2a); in addition, in the diarrheic calves, the mean age of the positive calves to BoNoV (10.3 days) was significantly lower than the

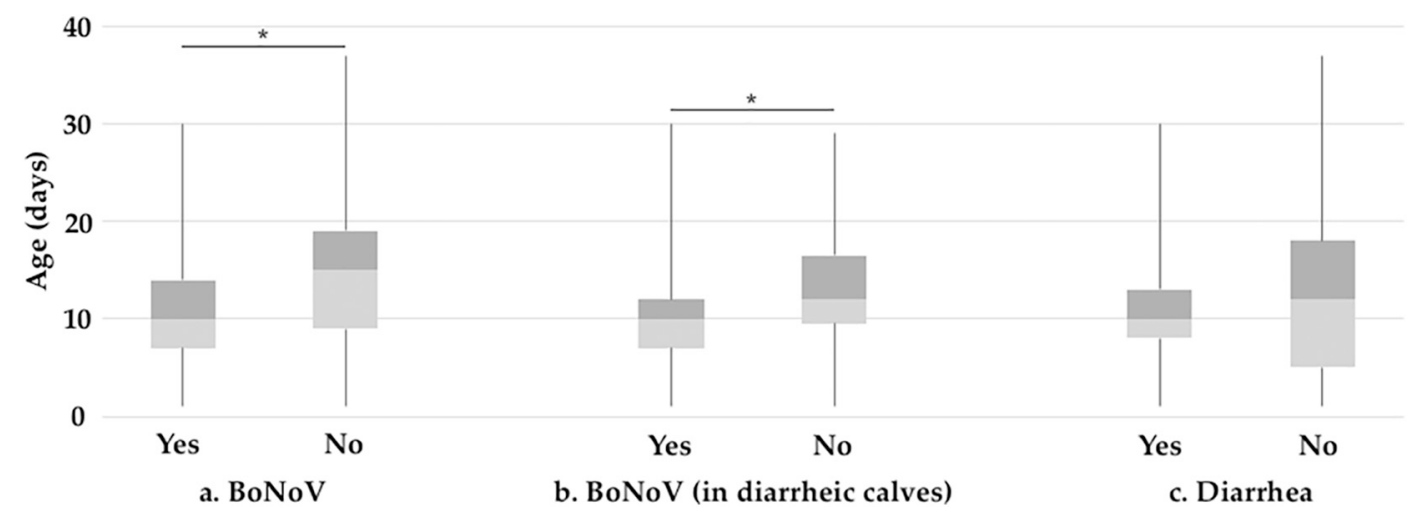

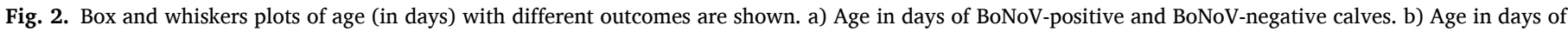

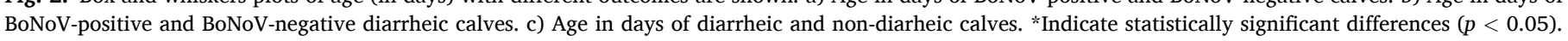


mean age of the negative ones (13.1 days; $p<0.001$ ) (Fig. 2b). Diarrheic calves (mean age of 10.9 days) were younger than non-diarrheic (mean age of 12.5 days) (Fig. 2c), and diarrheic BoNoV-positive calves were younger (mean age of 10.3 days) than non-diarrheic BoNoV-positive calves (mean age of 11.6 days), but these differences were not statistically significant ( $p=0.074$ and $p=0.093$, respectively).

The range of the Ct-values was 7.84-40.0 (Fig. 3) with a mean Ctvalue of 27.8 (SD 7.4) and a median Ct-value of 29.3. Thirty-five samples showed high viral load with Ct-values $<15,237$ showed Ct-values between 15 and 30, and 246 showed low viral load with Ct-values $>30$ (Fig. 3). In addition, we compare the Ct values among calf groups; we did not observe differences in the Ct values between diarrheic and non-diarrheic calves, and between alive and deceased calves. On the other hand, we observed lower Ct values in dairy (mean $\pm \mathrm{SD}$, $27.7 \pm 7.4)$ than beef $(32.2 \pm 7.9)$ calves $(p=0.026)$, and lower $\mathrm{Ct}$ values in calves $\leq 2$ weeks of age $(26.1 \pm 8.0)$ than older calves $(30.2 \pm$ $6.1, \mathrm{p}<0.001)$.

\subsection{Genetic diversity of BoNoV in Uruguay}

Thirty-four sequences were obtained from the 50 subjected to conventional PCR amplification. Twelve strains could not be sequenced because no or very low amplification, and four sequences were excluded from the analysis because showed chromatograms with double peaks, maybe due to coinfection. GIII.1 and GIII.2 genotypes were identified in four and 23 samples, respectively (Fig. 4). Three strains clustered within GIII.2, but together with recombinant strains, and one strain clustered together with Chinese strains with evidence of recombination and possessing a novel VP1 genotype (Fig. 4). Three sequences were shorter so were excluded from the analysis, but the three were GIII.2 (data not shown).

As some Uruguayan strains clustered together with recombinant strains, we performed several analyses to determine if these were also recombinant. SimPlot analysis showed evidence of recombination in the strains Bo/LVMS3019/2016/UY, Bo/LVMS3752/2017/UY, Bo/ LVMS3970/2017/UY, and Bo/LVMS3974/2017/UY (Fig. S1). The recombination breakpoints were observed in the junction ORF1-ORF2 in all the four strains. We confirmed these evidence with nucleotide sequences identity matrices: one performed with the partial $3^{\prime}$ end of the polymerase (RdRp, upstream the recombination breakpoints, Table 1), and another with the partial $5^{\prime}$ end of the capsid (downstream the recombination breakpoints, Table 1). This was confirmed also by phylogenetic analyses performed with the same two genomic regions used for the identity matrices (Fig. S2).

\section{Discussion}

The diarrheagenic and enteropathogenic potential of BoNoV have been well established in experimental infections in calves (Woode and Bridger, 1978; Jor et al., 2010; Otto et al., 2011; Jung et al., 2014), but under natural conditions has not yet been thoroughly studied, being relegated behind other pathogens such as rotavirus A, coronavirus, enterotoxigenic and enteropathogenic Escherichia coli, Cryptosporidium parvum, and Salmonella enterica, among others. However, studies have demonstrated its endemicity in several countries (Jor et al., 2010; Deng et al., 2003; van der Poel et al., 2003; Oliver et al., 2007; Mauroy et al., 2009; Thomas et al., 2014) and its role as enteric pathogen in calves (Di Felice et al., 2016), endorsing the need for epidemiological surveillance of BoNoV.

The frequency of BoNoV detection of $66.1 \%$ in this study was higher than the reported for other enteric viruses such as bovine rotavirus $\mathrm{A}$ (57\%) (Castells et al., 2020), bovine coronavirus (7.8\%) (Castells et al., 2019a) and bovine astrovirus (26\%) (Castells et al., 2019b) in cattle in Uruguay, in accordance with studies that have demonstrated that BoNoV could be the most commonly detected pathogen in calves' feces (Cho et al., 2013). In addition, the frequency observed in our study is higher than the reported for BoNoV in other countries including Argentina where the frequency of detection was 3.3\% (Ferragut et al., 2016), indicating that BoNoV is probably a belittled pathogen involved in calf diarrhea in Uruguay. The detection method used in our work (qPCR), probably has a higher sensitivity and specificity than the conventional PCR used in Argentina (Ferragut et al., 2016), which could partially explain this difference.

Despite their diarrheagenic and pathogenic potential under experimental conditions, whether BoNoVs represent a significant or even rare cause of spontaneous disease in cattle has not been widely studied. In our study the frequency of BoNoV detection was similar in diarrheic and non-diarrheic calves, as observed in The Netherlands (van der Poel et al., 2003); in USA, a higher frequency was observed in diarrheic calves, suggesting that this virus may be a significant contributor to calf diarrhea (Cho et al., 2013). Further investigations are needed to elucidate the clinical significance of the different BoNoV genotypes in spontaneous outbreaks of disease and eventual impact to the livestock industry. Several studies have demonstrated the prolonged shedding of the virus, before and after the manifestation of the diarrhea (Jor et al., 2010; Jung et al., 2014). Asymptomatic calves can spread the virus and their identification in the field is extremely difficult, which could have influenced the high frequency of detection observed in our study. The management of the calves in intensive systems is even more complicated, because separating only the diarrheic calves may not prevent the virus dispersion at the herd.

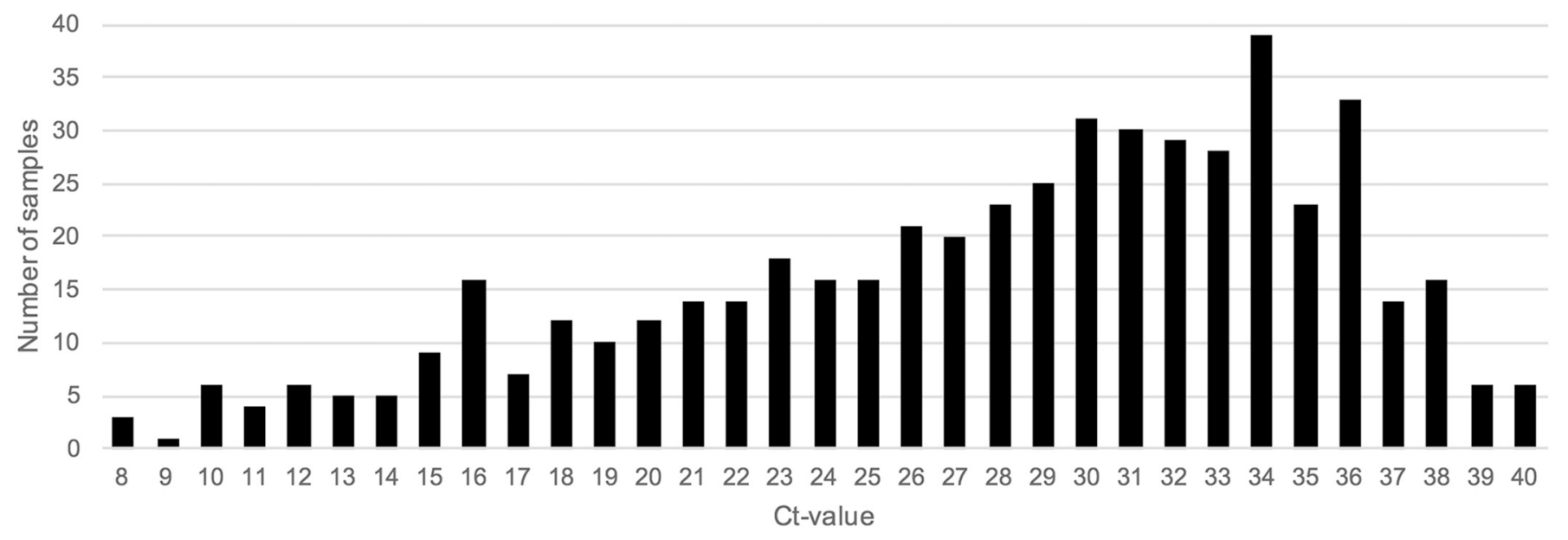

Fig. 3. Distribution of Ct-values (rounded to nearest integer value) of the BoNoV-positive samples. 


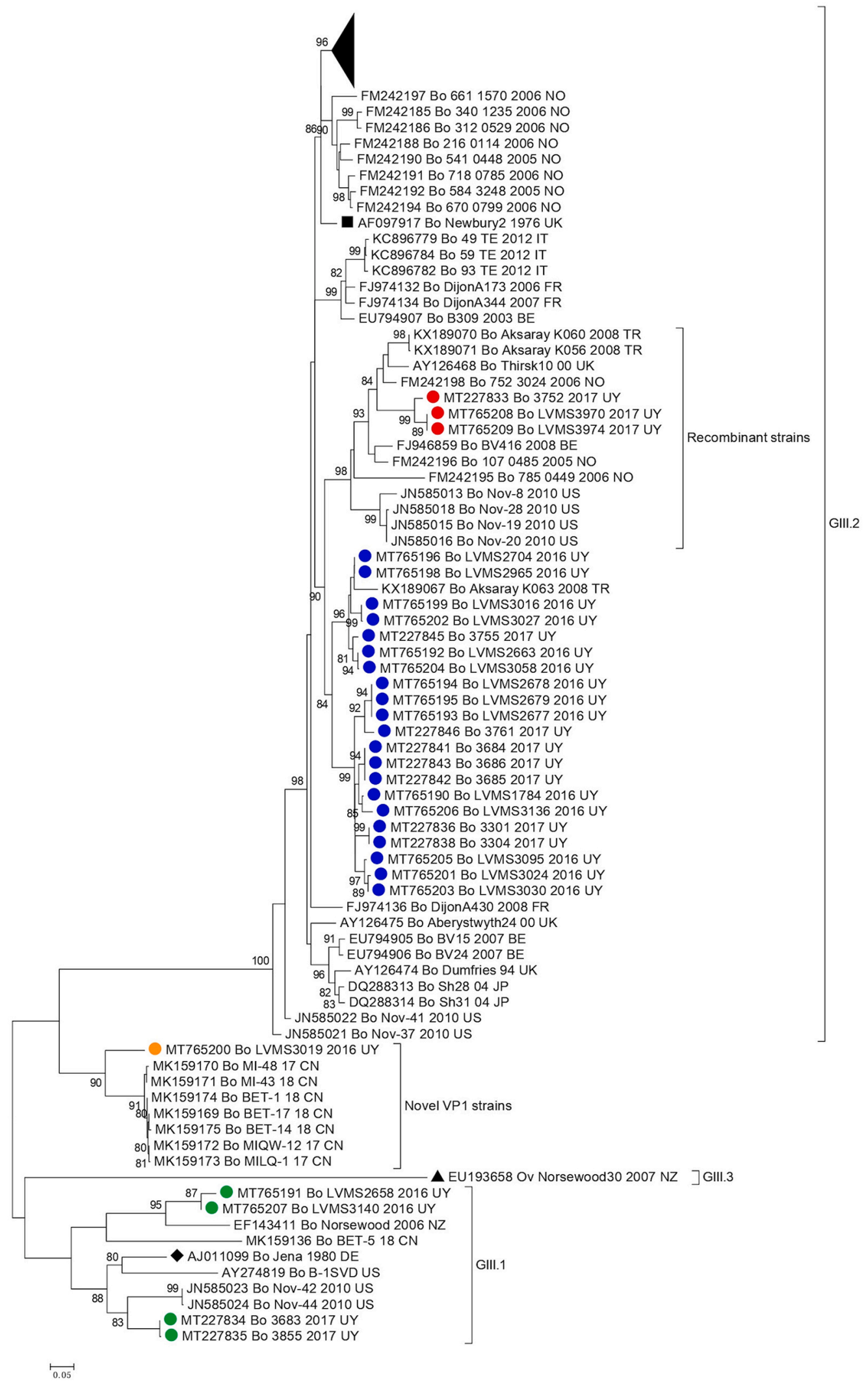

Fig. 4. Maximum likelihood tree with the TNe + I + G4 model obtained with IQ-TREE. Reference strains: Jena (GIII.1, black rhombus), Newbury2 (GIII.2, black square), and Norsewood30 (GIII.3, black triangle). Uruguayan strains are indicated with green circle (GIII.1), blue circle (GIII.2), orange circle (novel VP1), and red circle (recombinants GIII.P1-GIII.2). aLRT values higher than 80 are shown. (For interpretation of the references to colour in this figure legend, the reader is referred to the web version of this article.) 
Table 1

Sequence identity of Uruguayan recombinant strains compared with reference strains.

\begin{tabular}{|c|c|c|c|c|c|c|}
\hline & \multicolumn{3}{|c|}{$3^{\prime}$ end of RdRp } & \multicolumn{3}{|l|}{$5^{\prime}$ end Capsid } \\
\hline & Jena (GIII.1) & Newbury2 (GIII.2) & BET-17 (Novel VP1) & Jena (GIII.1) & Newbury2 (GIII.2) & BET-17 (Novel VP1) \\
\hline MT765208_Bo/LVMS3970/2017/UY & 0.986 & 0.934 & 0.947 & 0.740 & 0.857 & 0.784 \\
\hline MT765209_Bo/LVMS3974/2017/UY & 0.986 & 0.934 & 0.947 & 0.740 & 0.857 & 0.784 \\
\hline MT227833_Bo/3752/2017/UY & 0.986 & 0.934 & 0.947 & 0.745 & 0.864 & 0.774 \\
\hline MT765200_Bo/LVMS3019/2016/UY & 0.947 & 0.973 & 0.986 & 0.808 & 0.782 & 0.876 \\
\hline
\end{tabular}

The obtained Ct-values ranged from 7.84 to 40.0 , similar to the reported in Norway, where Ct-values ranged from 6.9 to 39.7 (Jor et al., 2010). Interestingly, we observed a right skewed distribution of Ctvalues, as previously reported, which may reflect prolonged low viral shedding post-clinical illness (Jor et al., 2010). Calves can be reinfected, prolonging the viral shedding without clinical signs, acting as reservoirs (Jor et al., 2010), which could reflect the high frequency of detection in non-diarrheic calves.

We observed that dairy calves were more often infected by BoNoV and with higher viral loads than beef calves, so studies about possible management conditions, geographic influence, and/or calves' genetic factors influencing this observation are encouraged.

Another factor studied was vaccination against NCD; it is important to clarify that vaccines do not include BoNoV, as there are no commercial vaccines available against this virus. BoNoV detection was higher in calves born to vaccinated dams but the difference was not statistically significant. Studies in humans (where vaccines against rotavirus A -RVA- but not norovirus are available as occurs in cattle) have demonstrated that vaccination against RVA have lead a reduction in RVA detection, leaving norovirus as the main cause of gastroenteritis in children (Hemming et al., 2013; Payne et al., 2013; Hemming-Harlo et al., 2016). In contrast, a study in diarrheic calves in France showed that vaccination against RVA did not promote the emergence of BoNoV (Kaplon et al., 2013), which is in concordance with the observed in our study. On the other hand, vaccines seem not to be effective against RVA in cattle (Castells et al., 2020), which could have influenced that no difference in BoNoV detection was observed.

The calves' age was analyzed as a factor that could influence the detection of BoNoV, and we observed that BoNoV was most commonly detected in the first two weeks of age, as observed in the USA (Smiley et al., 2003; Cho et al., 2013), indicating that younger calves are more frequently infected by BoNoV, and in this sense, the mean age of calves positive to BoNoV was lower than that of calves negative to the virus. In addition, the viral load was higher in calves $\leq 2$ weeks of age than older. Taken together, this data suggests that younger calves are more susceptible to BoNoV infection.

The phylogenetic analysis allowed to confirm that both main genotypes of BoNoV, GIII.1 and GIII.2, were circulating in Uruguay. The predominant genotype was GIII.2, as commonly observed in other countries (Mauroy et al., 2009; Kaplon et al., 2013; Thomas et al., 2014). Unfortunately, the sequence of the tentatively new genotype described in Argentina (Ferragut et al., 2016) was not available, thus, we could not determine if this genotype was circulating in Uruguay. The Uruguayan strains clustered in two lineages within GIII.1, in a divergent lineage divided in two sub-lineages within GIII.2, in a lineage together with GIII-P1/GIII.2 strains, and in a lineage together with Chinese strains recently described with a novel VP1 genotype, denoting a high genetic heterogeneity. The region amplified allowed the detection of possible recombinant strains, that were then confirmed by other specific methods. This region, then, is suitable for the detection and analysis of the genetic diversity of BoNoV (Jor et al., 2010). However, for a more accurate classification, complete genomes should be obtained.

Four Uruguayan strains showed recombination evidence, confirming the wide circulation of recombinant strains worldwide (Han et al., 2004; Oliver et al., 2004; Bull et al., 2007; Mauroy et al., 2009; Jor et al., 2010; Di Martino et al., 2014; Ferragut et al., 2016; Mohamed et al., 2018;
Karayel-Hacioglu and Alkan, 2019; Wang et al., 2019). This widely distribution of highly similar recombinant strains, may be due to ancestral recombination events that later spread widely in cattle. As for HIV (Reis et al., 2019), widely dispersed recombinant strains should be named BoNoV circulating recombinant forms (BoNoV CRFs), in order to facilitate the classification. A limitation of this study was the short length of the partial $3^{\prime}$ end of the polymerase, so the results related to recombination should be taken with caution. Three of the four recombinant strains were GIII.1/GIII.2, the most widely dispersed CRF. Most of the GIII.1/GIII.2 recombinant clustered together, further supporting a common origin. Interestingly, one strain clustered with recombinant strains with a novel VP1 genotype (Wang et al., 2019), which suggests that probably this novel VP1 genotype is widely dispersed, and maybe has been overlooked.

In conclusion, this was the first study on BoNoV conducted in Uruguay, and revealed a high frequency of BoNoV infection in diarrheic and non-diarrheic calves, with higher frequency in dairy than in beef calves. Calves $\leq 2$ weeks of age were infected more often than older calves. Both main genotypes, GIII.1 and GIII.2, were identified, and four recombinant strains were described. Despite no clear association was found with NCD, the results of our study indicate that BoNoV may be a belittled pathogen involved in calf diarrhea.

Supplementary data to this article can be found online at https://doi. org/10.1016/j.meegid.2020.104613.

\section{Declaration of Competing Interest}

None.

\section{Acknowledgments}

This work was funded by "Comisión Sectorial de Investigación Científica” (CSIC), grant number ini2017_158. M.C. acknowledges support from the "Agencia Nacional de Investigación e Innovación" (ANII) through a $\mathrm{PhD}$ scholarship, and "Comisión Sectorial de Investigación Científica" (CSIC) and ANII for mobility fellowships.

\section{References}

Bull, R.A., Tanaka, M.M., White, P.A., 2007. Norovirus recombination. J. Gen. Virol. 88 (Pt 12), 3347-3359. https://doi.org/10.1099/vir.0.83321-0.

Castells, M., Giannitti, F., Caffarena, R.D., Casaux, M.L., Schild, C., Castells, D., RietCorrea, F., Victoria, M., Parreño, V., Colina, R., 2019a. Bovine coronavirus in Uruguay: genetic diversity, risk factors and transboundary introductions from neighboring countries. Arch. Virol. 164 (11), 2715-2724. https://doi.org/10.1007/ s00705-019-04384-w.

Castells, M., Bertoni, E., Caffarena, R.D., Casaux, M.L., Schild, C., Victoria, M., RietCorrea, F., Giannitti, F., Parreño, V., Colina, R., 2019b. Bovine astrovirus surveillance in Uruguay reveals high detection rate of a novel Mamastrovirus species. Viruses 27;12 (1), E32. https://doi.org/10.3390/v12010032.

Castells, M., Caffarena, R.D., Casaux, M.L., Schild, C., Miño, S., Castells, F., Castells, D., Victoria, M., Riet-Correa, F., Giannitti, F., Parreño, V., Colina, R., 2020. Phylogenetic analyses of rotavirus a from cattle in Uruguay reveal the circulation of common and uncommon genotypes and suggest interspecies transmission. Pathogens. 9 (7), 570. https://doi.org/10.3390/pathogens9070570.

Cho, Y.I., Han, J.I., Wang, C., Cooper, V., Schwartz, K., Engelken, T., Yoon, K.J., 2013. Case-control study of microbiological etiology associated with calf diarrhea. Vet. Microbiol. 166 (3-4), 375-385. https://doi.org/10.1016/j.vetmic.2013.07.001.

Deng, Y., Batten, C.A., Liu, B.L., Lambden, P.R., Elschner, M., Günther, H., Otto, P., Schnürch, P., Eichhorn, W., Herbst, W., Clarke, I.N., 2003. Studies of epidemiology 
and seroprevalence of bovine noroviruses in Germany. J. Clin. Microbiol. 41 (6), 2300-2305. https://doi.org/10.1128/jcm.41.6.2300-2305.2003.

van Der Poel, W.H., Vinjé, J., van Der Heide, R., Herrera, M.I., Vivo, A., Koopmans, M.P., 2000. Norwalk-like calicivirus genes in farm animals. Emerg. Infect. Dis. 6 (1), 36-41. https://doi.org/10.3201/eid0601.000106.

Di Felice, E., Mauroy, A., Pozzo, F.D., Thiry, D., Ceci, C., Di Martino, B., Marsilio, F., Thiry, E., 2016. Bovine noroviruses: a missing component of calf diarrhoea diagnosis. Vet. J. 207, 53-62. https://doi.org/10.1016/j.tvjl.2015.10.026.

Di Martino, B., Di Profio, F., Di Felice, E., Melegari, I., Ceci, C., Mauroy, A., Thiry, E., Martella, V., Marsilio, F., 2014. Genetic heterogeneity of bovine noroviruses in Italy. Arch. Virol. 159 (10), 2717-2722. https://doi.org/10.1007/s00705-014-2109-0. Oct.

DIEA, 2019. Anuario Estadístico Agropecuario. Available online at: https://descargas. mgap.gub.uy/DIEA/Anuarios/Anuario2019/Anuario2019.pdf. Accessed 6th March, 2020.

Donovan, G.A., Dohoo, I.R., Montgomery, D.M., Bennett, F.L., 1998. Calf and disease factors affecting growth in female Holstein calves in Florida, USA. Prev. Vet. Med. 33 (1-4), 1-10. https://doi.org/10.1016/s0167-5877(97)00059-7.

Ferragut, F., Vega, C.G., Mauroy, A., Conceição-Neto, N., Zeller, M., Heylen, E., Uriarte, E.L., Bilbao, G., Bok, M., Matthijnssens, J., Thiry, E., Badaracco, A., Parreño, V., 2016. Molecular detection of bovine noroviruses in Argentinean dairy calves: circulation of a tentative new genotype. Infect. Genet. Evol. 40, 144-150. https://doi.org/10.1016/j.meegid.2016.02.034.

Food and Agriculture Organization of the United Nations, 2018. Meat Market Review. April. FAO, Rome.

Han, M.G., Smiley, J.R., Thomas, C., Saif, L.J., 2004. Genetic recombination between two genotypes of genogroup III bovine noroviruses (BoNVs) and capsid sequence diversity among BoNVs and Nebraska-like bovine enteric caliciviruses. J. Clin. Microbiol. 42 (11), 5214-5224. https://doi.org/10.1128/JCM.42.11.5214 5224.2004.

Hemming, M., Räsänen, S., Huhti, L., Paloniemi, M., Salminen, M., Vesikari, T., 2013. Major reduction of rotavirus, but not norovirus, gastroenteritis in children seen in hospital after the introduction of RotaTeq vaccine into the National Immunization Programme in Finland. Eur. J. Pediatr. 172 (6), 739-746. https://doi.org/10.1007/ s00431-013-1945-3.

Hemming-Harlo, M., Markkula, J., Huhti, L., Salminen, M., Vesikari, T., 2016. Decrease of rotavirus gastroenteritis to a low level without resurgence for five years after universal RotaTeq vaccination in Finland. Pediatr. Infect. Dis. J. 35 (12), 1304-1308. https://doi.org/10.1097/INF.0000000000001305.

International Dairy Federation, 2013. The world dairy situation 2013. Bull. Intern. Dairy Feder. 470 (/2013)

Jor, E., Myrmel, M., Jonassen, C.M., 2010. SYBR Green based real-time RT-PCR assay for detection and genotype prediction of bovine noroviruses and assessment of clinica significance in Norway. J. Virol. Methods 169 (1), 1-7. https://doi.org/10.1016/j. jviromet.2010.03.028.

Jung, K., Scheuer, K.A., Zhang, Z., Wang, Q., Saif, L.J., 2014. Pathogenesis of GIII.2 bovine norovirus, CV186-OH/00/US strain in gnotobiotic calves. Vet. Microbiol. 168 (1), 202-207. https://doi.org/10.1016/j.vetmic.2013.11.008.

Kaplon, J., Fremy, C., Bernard, S., Rehby, L., Aho, S., Pothier, P., Ambert-Balay, K., 2013. Impact of rotavirus vaccine on rotavirus genotypes and caliciviruses circulating in French cattle. Vaccine. 7 (31), 20, 2433-40. https://doi.org/10.1016/j.vaccine.20 13.03.039.

Karayel-Hacioglu, I., Alkan, F., 2019. Molecular characterization of bovine noroviruses and neboviruses in Turkey: detection of recombinant strains. Arch. Virol. 164 (5), 1411-1417. https://doi.org/10.1007/s00705-019-04186-0.

Kumar, S., Stecher, G., Tamura, K., 2016. MEGA7: molecular evolutionary genetics analysis version 7.0 for bigger datasets. Mol. Biol. Evol. 33 (7), 1870-1874. https:// doi.org/10.1093/molbev/msw054.

Mann, H.B., Whitney, D.R., 1947. On a test of whether one of two random variables is stochastically larger than the other. Ann. Math. Stat. 18, 50-60.

Mauroy, A., Scipioni, A., Mathijs, E., Saegerman, C., Mast, J., Bridger, J.C., Ziant, D., Thys, C., Thiry, E., 2009. Epidemiological study of bovine norovirus infection by RTPCR and a VLP-based antibody ELISA. Vet. Microbiol. 137 (3-4), 243-251. https:// doi.org/10.1016/j.vetmic.2009.01.031, 12.

Milnes, A.S., Binns, S.H., Oliver, S.L., Bridger, J.C., 2007. Retrospective study of noroviruses in samples of diarrhoea from cattle, using the Veterinary Laboratories Agency's Farmfile database. Vet. Rec. 160 (10), 326-330. https://doi.org/10.1136/ vr.160.10.326.
Mohamed, F.F., Ktob, G.K.F., Ismaeil, M.E.A., Ali, A.A.H., Goyal, S.M., 2018. Phylogeny of bovine norovirus in Egypt based on VP2 gene. Int. J. Vet. Sci. Med. 6 (1), 48-52. https://doi.org/10.1016/j.ijvsm.2018.04.005.

Oliver, S.L., Brown, D.W., Green, J., Bridger, J.C., 2004. A chimeric bovine enteric calicivirus: evidence for genomic recombination in genogroup III of the norovirus genus of the Caliciviridae. Virology. 326 (2), 231-239. https://doi.org/10.1016/j. virol.2004.06.010.

Oliver, S.L., Wood, E., Asobayire, E., Wathes, D.C., Brickell, J.S., Elschner, M., Otto, P., Lambden, P.R., Clarke, I.N., Bridger, J.C., 2007. Serotype 1 and 2 bovine noroviruses are endemic in cattle in the United Kingdom and Germany. J. Clin. Microbiol. 45 (9), 3050-3052. https://doi.org/10.1128/JCM.02015-06.

Otto, P.H., Clarke, I.N., Lambden, P.R., Salim, O., Reetz, J., Liebler-Tenorio, E.M., 2011. Infection of calves with bovine norovirus GIII.1 strain Jena virus: an experimental model to study the pathogenesis of norovirus infection. J. Virol. 85 (22), 12013-12021. https://doi.org/10.1128/JVI.05342-11.

Payne, D.C., Vinjé, J., Szilagyi, P.G., Edwards, K.M., Staat, M.A., Weinberg, G.A., Hall, C. B., Chappell, J., Bernstein, D.I., Curns, A.T., Wikswo, M., Shirley, S.H., Hall, A.J., Lopman, B., Parashar, U.D., 2013. Norovirus and medically attended gastroenteritis in U.S. children. N. Engl. J. Med. 368 (12), 1121-1130. https://doi.org/10.1056/ NEJMsa1206589.

van der Poel, W.H., van der Heide, R., Verschoor, F., Gelderblom, H., Vinjé, J., Koopmans, M.P., 2003. Epidemiology of Norwalk-like virus infections in cattle in the Netherlands. Vet. Microbiol. 92 (4), 297-309. https://doi.org/10.1016/s0378-1135 (02)00421-2.

Reis, M.N.G., Guimarães, M.L., Bello, G., Stefani, M.M.A., 2019. Identification of new HIV-1 circulating recombinant forms CRF81_cpx and CRF99_BF1 in Central Western Brazil and of unique BF1 recombinant forms. Front. Microbiol. 10, 97. https://doi. org/10.3389/fmicb.2019.00097.

Scipioni, A., Mauroy, A., Vinjé, J., Thiry, E., 2008. Animal noroviruses. Vet. J. 178 (1), 32-45. https://doi.org/10.1016/j.tvjl.2007.11.012.

Selman, I.E., 1981. The care of young calves, neonatal calf diarrhea, the calf pneumonias. In: Ristic, M., McIntyre, I. (Eds.), Diseases of cattle in the Tropics. Current Topics in Veterinary Medicine and Animal Science, vol 6. Springer, Dordrecht. https://doi. org/10.1007/978-94-015-6895-1_39.

Shapiro, S.S., Wilk, M.B., 1965. An analysis of variance test for normality (complete samples). Biometrika 52 (3-4), 591-611. https://doi.org/10.1093/biomet/52.34.591.

Smiley, J.R., Hoet, A.E., Tråvén, M., Tsunemitsu, H., Saif, L.J., 2003. Reverse transcription-PCR assays for detection of bovine enteric caliciviruses (BEC) and analysis of the genetic relationships among BEC and human caliciviruses. J. Clin. Microbiol. 41 (7), 3089-3099. https://doi.org/10.1128/jcm.41.7.3089-3099.2003.

Thomas, C., Jung, K., Han, M.G., Hoet, A., Scheuer, K., Wang, Q., Saif, L.J., 2014. Retrospective serosurveillance of bovine norovirus (GIII.2) and nebovirus in cattle from selected feedlots and a veal calf farm in 1999 to 2001 in the United States. Arch. Virol. 159 (1), 83-90. https://doi.org/10.1007/s00705-013-1795-3.

Trifinopoulos, J., Nguyen, L.T., von Haeseler, A., Minh, B.Q., 2016. W-IQ-TREE: a fast online phylogenetic tool for maximum likelihood analysis. Nucleic Acids Res. 44 (W1), W232-W235.

Urie, N.J., Lombard, J.E., Shivley, C.B., Kopral, C.A., Adams, A.E., Earleywine, T.J., Olson, J.D., Garry, F.B., 2018. Preweaned heifer management on US dairy operations: part V. factors associated with morbidity and mortality in preweaned dairy heifer calves. J. Dairy Sci. 101 (10), 9229-9244. https://doi.org/10.3168/ jds.2017-14019.

Waltner-Toews, D., Martin, S.W., Meek, A.H., 1986. The effect of early calfhood health status on survivorship and age at first calving. Can. J. Vet. Res. 50 (3), 314-317.

Wang, Y., Yue, H., Tang, C., 2019. Prevalence and complete genome of bovine norovirus with novel VP1 genotype in calves in China. Sci. Rep. 9 (1), 12023. https://doi.org/ 10.1038/s41598-019-48569-4.

Wolf, S., Williamson, W.M., Hewitt, J., Rivera-Aban, M., Lin, S., Ball, A., Scholes, P., Greening, G.E., 2007. Sensitive multiplex real-time reverse transcription-PCR assay for the detection of human and animal noroviruses in clinical and environmental samples. Appl. Environ. Microbiol. 73 (17), 5464-5470. https://doi.org/10.1128/ AEM.00572-07.

Woode, G.N., Bridger, J.C., 1978. Isolation of small viruses resembling astroviruses and caliciviruses from acute enteritis of calves. J. Med. Microbiol. 11 (4), 441-452. https://doi.org/10.1099/00222615-11-4-441. 